\title{
Job Satisfaction and Teacher Retention in Selected Senior High School in Ghana
}

\author{
* Akaribo William Aduko, Med. Augustine Adjei ${ }^{1}$ Med. /Mphil. Akuta Bertha Azaare ${ }^{2}$ Med \\ * Gbewaa College of Education, Upper East Region, Ghana West Africa \\ 1. Offinso College of Education, Ashanti Region, Ghana West Africa \\ 2. St. AmbroseCollege of Education, Bono Region, Ghana West Africa
}

\begin{abstract}
The study investigated into job satisfaction and teacher retention. Fifty teachers who were made up of 36 males and 14 females were randomly sampled. Questionnaire was used in the data collection. The data gathered was scored with a likert scale. The raw scores were entered into the Statistical Package for the Social Sciences(SPSS) Software System. The first research question sought to find out what factors contributed to job satisfaction among teachers at Zuarungu Senior High School. A good number of the teachers agreed to factors such as salary, accommodation and administrative support contributing to job satisfaction. The second research question was to find out in what ways job dissatisfaction affected teachers' performance in Zuarungu Senior High School. Majority agreed that absenteeism, refusal to do assigned duties, not setting and marking of examstimely are some of the effects of job dissatisfaction. Research question three was to find out what factors influenced teachers' decision to quit teaching in Zuarungu Senior High School. The teachers responded to the following factors that would compel them to quit teaching; no provision of accommodation for teachers and non-payments of allowances due them. Research question four was to find out effective ways of attracting and retaining teachers in Zuarungu Senior High School. The teachers agreed that provision of accommodation, payment of allowances and soft loans would attract them to the school. The analysis was summarized and concludedthat employees, especially teachers leave the teaching field because they are not satisfied with theirjob as a result of poor working conditions. They study recommended that Ghana Education Service should provide goodworking conditions like provision of accommodation and timely payment of allowances to mitigate their decision to quit teaching which in the long run affects the performances of the innocent school children. It was suggested that the research should be widened tocover more schools in the municipality.
\end{abstract}

Keywords: Learning Experience, Educational preparation, Social and Professional Integration and Teacher' Personal Characteristics

\section{Background to the Study}

The impact of employee turnover intentions on organizational effectiveness and employee morale hasremained the focus of organizational researchers in recent times (Chen, Polyhart, Thomas, Anderson, \& Bliese,2011; Kacmar, Andrews, Van Rooy, Steilberg, \&Cerrone, 2006; Pitts, Marvel, \&Fernandez, 2011; Sean, Godkin, Fleischman, \& Kidwell, 2010; Shaw, Gupta, \&Delery, 2005). Based on the envisaged negative impact of turnover intentions on organizations, managers seek better ways to manage their employees in order to retainvalued human resources and sustain high performance.Meyer (1993) defined turnover intentions as conscious wilfulness to seek other alternative jobopportunities in other organization. For education to serve its purpose of making life more meaningful, it must be of high quality. In Ghana, the quality of education is linked among other things to the ability of the recipient to live and to be useful to the community. It is this notion of quality education that underscores the on-going Education Reform Programme introduced in 1987 by the Ghana government. 
The reforms have concentrated on providing infrastructure and things like textbooks, furniture, classrooms and workshops. Teacher training colleges are turned into colleges of education which award diploma certificates to their students. This is to ensure that the teachers turned out are competent enough to provide quality education to the students. Access to tertiary education has been increased. Admissions have been expanded in the universities to take in more students. Every region has a polytechnic to absorb the vast number of students that senior high schools turn out every year. This has a two-fold advantage; First, it helps to train the large number of teachers who are needed to provide quality education in the senior high institutions. Second, it serves as a form of motivation to encourage otherwise frustrated teachers who need further education to better their lot and return to the classroom. This suggests that higher qualification of teachers is an important aspect of the educational reforms.

Some concrete steps have been taken by government to motivate teachers already in the classroom. The National Best Teacher Award was instituted to spur teachers on. However, in spite of all these, some people believe that for teachers to feel satisfied and stay for long at post requires other consideration. It is necessary to explore other ways to keeping our teachers happy and satisfied, hence the relevance of this research. The research is been carried out to find out how to enhance satisfaction and productivity among teachers in senior high schools. In Zuarungu Senior High School, teachers when posted to the school do not stay for long and leave for other sectors of the economy and this has being a problem in the Bolgatanga Municipality hence the need to research into it and recommend measures to adopt to help reduce it if not stop completely.

\section{Statement of the problem}

Tutor attrition has been almost a permanent feature of senior high schools in the Bolgatanga Municipality for the past years. At the beginning of each academic year, the schools witness the departure or absence of a significant number of qualified teachers and very few of the tutors posted to this school stay on for more than five years. Almost invariably, such departing tutors from Zuarungu Senior High School leave for other places to work. This has affected student's academic performance in their final examinations since some teachers do not finish the syllabus with their students before leaving. Again, teachers who desire to quit teaching are less likely to devote themselves to teaching. Students' discipline is yet another effect of teachers' attrition since teachers who are new in the school do not know much about the students. This makes it difficult to track their behaviours. Ordinarily, it takes some period for both teachers and students to get used to each other. It is even more difficult in Zuarungu Senior High School since teachers do not stay for long on the job but leave for other sectors of the economy to work. The school has difficulty in getting tutors to stay and work for longer than five years. This problem has necessitated an inquiry into the cause of teachers not staying long at Zuarungu Senior High School.

\section{Purpose of the study}

This study set out to investigate the nature of the existing work environment at Zuarungu Senior High School and find out whether or not such a work environment has any effect on tutor motivation. It was also to look at the factors that contribute to satisfaction among tutors and then suggest intervention strategies to improve the situation in order to retain tutors in the school.

\section{Objectives of the Study}

The objectives of the study were:

1. To find out the factors that contribute to job satisfaction in Zuarungu Senior High School.

2. To find out the influence of job dissatisfaction on teachers' performance.

\section{Research Questions}

The following research questions have been formulated to guide the researcher in this study.

1. What factors contribute to job satisfaction among teachers at Zuarungu Senior High School?

2. In what conditions does teachers' job dissatisfaction affect teachers' performance in Zuarungu Senior High School?

\section{Significance of the study}


The significance of this study lies in the fact that when the results are made available they will guide the educational planners and other stakeholders like school administrators to easily identify the problems of teachers. It would also offer appropriate solutions for those problems. In this way, there will be collective improvement of the performance of teachers and this will enhance the quality of education in schools. This study is expected to bring to light those factors in the work environment that contribute to dissatisfaction among tutors of the schools. This exposition will go a long way in guiding the authorities to look for avenues to better the situation not only for retaining tutors but also for the general progress of the school.Findings from the study will serve as an eye-opener for authorities of other institutions operating under similar work conditions thus helping to improve conditions for tutor-retention in Ghana.

\section{Limitations of the study}

The population for the study was small. The finding could therefore be applicable only to schools with similar conditions. The research design was a case study. Also, because of the requirements of the university the time allocation for this work was too limited for all aspects of the issues of job satisfaction to be examined. Lack of money to carry out an extensive research limited this work to only one institution in the municipality. Again, respondents most probably gave favourable responses to the questionnaire if they thought their answers could jeopardize or at least sour the relationship with the headmistress though confidentiality was assured.

\section{Delimitations}

But for constraintsof time and finance, this study should have been extended to other schools in the municipality with similar problems. However, it was limited to Zuarungu Senior High School, firstly, because the problem had been found to be endemic at Zuarungu Senior High School. Secondly, the researcher had a first-hand experience for the past two years.

\section{Human Capital Theory}

Ones decision to quit teaching or stay on the job will depend on a number of factors

Human capital theory provides a useful framework of understanding some underlying factors that may contribute to an individual's decision to become a teacher, and subsequently, to remain in or leave teaching. Generally speaking, human capital theory identifies teacher's attrition on the basis of the real or perceived value of the job in relation to the investment an individual has made to become a teacher (Becker, 2001; Ehrenberg \& Smith, 2003). One of the major principles of human capital theory is that the greater the amount of knowledge and skills accumulated in a job over time from investments in education and job training, the lower one's probability of one's decision to quit from that occupation (Ehrenberg \& Smith, 2003; Kirby \& Grissmer, 2004). Focusing on the costs and benefits, if the present value of the benefits associated with attrition exceeds the costs, people will make a decision to change.

In other words, teachers whose foregone rewards (i.e., opportunity costs of teaching) outweigh the rewards gained from teaching will be more likely to leave the teaching profession. This theory basically illustrates the relationships among education and training, migration and the search for a new job in terms of investment and its returns (Becker, 2001; Ehrenberg \& Smith, 2003). Expected utilities from attrition decisions are influenced by entry requirements (e.g., licensure), and future benefits such as better salary (monetary rewards), working conditions (non-pecuniary attribute), and professional training benefits. If the present value of the benefits associated with attrition exceeds the costs, individuals are more likely to make a decision to change jobs.

\section{Meaning of job satisfaction}

Job satisfaction is used to refer to the degree to which a teacher is happy with his or her success in meeting his or her career goals and expectations (Heller 2005). Job satisfaction is an effective response to specific aspects of a job such as challenge, inherent interest and level of difficulty. These aspects of the job situation have been found to play a large role in determining the overall level of people's job satisfaction. When a person is satisfied with his or her job, it means he or she is happy with his or her current status and is prepared to remain there and contribute his or her maximum towards the success of the organization.Robbins (1999) refers to job satisfaction as an individual's general attitudes towards his or her job. A person with high level of job satisfaction holds positive attitude towards the job, while a person who 
is dissatisfied with his or her job holds a negative attitude towards the job. He also believes that satisfaction is also probably strongly influenced by economic conditions.

He notes that satisfaction is strongly and consistently negatively related to an employee's decision to stay or leave the organization. Although satisfaction and absence are also negatively related, people should be careful in drawing conclusions regarding the relationship.

The importance of high job satisfaction is three- fold and managers should be concerned with the level of job satisfaction in their organizations:Firstly, there is clear evidence that dissatisfied employees absent themselves from work more often and are more likely to resign. Satisfied employees have lower rates of thought of quitting and absenteeism. In 2013, five teachers at Zuarungu Senior High School left for Volta River Authority and private companies respectively according to the headmistress's end of year report2012/2013 academic year report.Secondly, it has been demonstrated that satisfied employees have better health and live longer. Several studies have shown that employees who are dissatisfied with their jobs are prone to health setbacks ranging from headaches to heart diseases. Some studies have suggested that job satisfaction is a better predictor of length of life than is physical condition or tobacco use. The stress that results from dissatisfaction apparently increases one's susceptibility to heart attacks and the like. Therefore, even if satisfaction did not lead to less attrition and absence, the goal of a satisfied workforce might be justifiable because it would reduce medical cost and the premature loss of valued employees by way of sickness or death.

Also, satisfaction on the job comes over to the employee's life outside the job. Job satisfaction has a spin-off effect. When employees are happy with their jobs, it improves their lives off the job. In contrast, the dissatisfied employee carries that negative attitude home.

In conclusion, Robbins says for management, satisfied workforce translates into higher productivity due to fewer disruptions caused by absenteeism or good employees quitting and lower medical and life insurance cost. For the society, satisfaction on the job carries over to the employee's off-the-job hours. Robbins (1999) identifies four dependent variables that enhance satisfaction namely-mentally-challenging work, equitable rewards, supportive working conditions and supportive colleagues.

\section{Mentally Challenging Work}

On the issue of mentally challenging work, Robbins explains that employees tend to prefer jobs that give them opportunities to use their skills and abilities and offer a variety of task, freedom and feedback on how well they are doing. Under conditions of moderate challenge, most employees will experience pleasure and satisfaction.

\section{Equitable Rewards}

To Robbins (199), promotions provide opportunities for personnel growth, more responsibilities and increased social status. Individuals who perceive that promotion decisions are made in a fair and just manner, therefore, are likely to experience satisfaction from the job. In the same vein, a feeling of unfairness in promotion leads to dissatisfaction.

\section{Supportive Working Conditions}

Supportive working conditions are very important factors that affect ones decision to quit teaching or stay on the teaching.Denyer 2000 says employees are concerned with their work environment for both personal comfort and facilitating a good job. Most employees prefer relatively close to home, in clean and relatively modern facilities and with adequate tools and equipment. Denyer (2000) also emphasized that since staff do better work in good conditions, it is good economics to provide the best working conditions possible within the limitation of finance and the type of accommodation.

\section{Monetary Benefits}

From the perspective of Human Capital Theory, monetary benefits (e.g., health/life insurance, pensions) from the teaching profession can be viewed as returns on investment in education and training. Such training may make individuals more productive, resulting in higher wages and the trade-offs associated with the costs (Becker, 1993). Generally speaking, if teachers feel that their return is being lowered as they work, 
they will be less likely to invest in training and thus leave. In other words, teachers who have perceived that they have put too much into teaching but have not gotten enough in return decide to leave (Becker, 1993).

\section{Non-monetary Benefits}

Along with monetary benefits, teachers consider non-monetary benefits as one of the most important factors affecting their career decisions. In general, non-monetary benefits may include support from fellow teachers and administrators, the quality of school facilities and resources available, autonomy in classroom, participation in school decision-making, student learning attitudes, and assigned teaching hours are generally considered as working conditions(Barro, 1992; Ingersoll,2001).Scholars differentiate between firm-specific and generic human capital. Firm-specific human capital refers to factors that cannot be transferred to other schools, while generic human capital is one which can be easily transferred to other schools and professions. Firm specific human capital includes knowledge of school practices, seniority in the system, respect of colleagues, and other forms of autonomy and privilege (Becker, 1993; Black, 2002; Grissmer \& Kirby, 1997). In principle, the more firm-specific human capital that is built up, the less likely an individual is to leave that profession if the human capital is rewarded (Kirby \& Grissmer, 1997). This implies that teachers at the study that is Zuarungu Senior High School if they see teaching as rewarding may stay while those who do not see it rewarding may also quit. Working conditions and/or school level characteristics contribute significantly to teachers' decisions about where to work, along with monetary benefits. Compared to monetary benefits, working conditions have received less attention in earlier literature (Barro, 2003; Ingersoll, 1997).

\section{Professional Training Benefits}

Individuals increase their store of human capital through formal schooling and on-the job training which includes induction/mentoring programmes and professional development programmes. Training as investment in human capital can be labeled as general or specific.

General training that accumulates generic human capital can be defined as any training that can be easily transferred to other professions and can increase an individual's future wages or benefits (Kirby \&Grissmer, 1993). In contrast, specific training that builds up firm-specific human capital can be defined as training which is specific to the school in which a teacher teaches or another school in the district (Kirby \&Grissmer, 1993).Human capital theory conceptualizes decisions individuals make to stay in or leave teaching as rational and based on the real or perceived value of the job versus the investment made to become a teacher.

\section{Dual-Factor Job Satisfaction Theory}

Various theorists have proposed models that map out the various sources of satisfaction and dissatisfaction for job satisfaction in general and for teacher satisfaction in particular. The essential underlying conceptual difficulty associated with researching job satisfaction is that there is no agreed upon definition of the term.Often cited in education literature, Herzberg's (1968) Dual-Factor Job Satisfaction theory suggests that there are two dimensions of job satisfaction: motivation and hygiene.The motivator or intrinsic rewards include recognition, achievement, possibility of growth, advancement, responsibility, and work itself (Hirsch, 2001). Motivator factors cause positive job attitudes because they satisfy the worker's need for selfactualization which is an individual's ultimate goal. Many enter teaching because they want to make a difference with children by successfully meeting their academic needs .Therefore, teachers are satisfied according to this view, when they can facilitate learning and cultivate positive relationships with students. The hygiene or extrinsic dimension is similar to that explained by human capital theory. This dimension includes salary, supervision, administrative policies, working conditions, and interpersonal relations (Herzberg, 1968).

\section{Herzberg's two factor Motivation and Job Satisfaction}

Herzberg's (1968) theory was designed to discover the importance of attitudes towards work and experiences, both good and bad, reported by workers. The theory also purported to differentiate between intrinsic and extrinsic aspects of the job. The question then is, what do people want from their jobs? Herzberg, Mausner and Synderman (1968), interviewed two hundred and three (203) accountants and engineers, asked them to relate the time when they felt exceptionally good or exceptionally bad about their job or any previous jobs. They were asked to give reasons and a description of the sequence of events giving 
rise to that feeling. They concluded that good working conditions, hygiene and good work (motivator) are needed to effect job satisfaction.

\section{Supportive Colleagues}

In connection with this, Robbins says people get more out of their work than merely receiving money or tangible achievements. For instance, living with friendly and supportive co-workers leads to increased satisfaction. A quick look at any organization suggests that some people work harder than others. Often, others with inferior talents outperform people of outstanding abilities. This shows that people exert different levels of effort in different activities. The idea of motivation comes to mind here. Why do some people appear to be 'highly motivated' whereas others are not?

\section{Effective ways to attract and retain teachers e.g. motivation}

Motivation is very vital in all organizations because it determines performance. Motivation is defined as 'the willingness to exert high levels of effort toward organizational goals, conditioned by the efforts and ability to satisfy some individual needs'. The import of the definition is that, to motivate somebody is to stimulate the person's interest, or to cause him to do something. From the manager's point of view therefore, the objective is to behave in ways that are in the organization's interest. This means getting people to perform at a high level by making them work hard regularly and make positive contributions to the organization's mission (Moorhead \& Griffin, 2005).By Moorhead \& Griffin's definition, if conditions that favour the teachers in Zuarungu Senior High School are provided, will urge them to behave in certain ways which in this case means staying and teaching effectively at the school.

\section{Mullins' Theory of Motivation}

Mullins (2005), the objectives of an organization can only be achieved through the combined efforts of its members. The relationship between the organization and its members is governed by what motivates them to work and the fulfilment they derive from it. The manager needs to understand how to elicit the co-operation of staff and direct their performance to achieve the goals and the objectives of the organization. He notes, 'the manager must know how best to motivate staff so that they work willingly and effectively'.

Mullins (2005) adopts the definition of Mitchell as motivation being 'the degree to which an individual wants and chooses to engage in certain specified behaviours'. The underlying concept of motivation is achieving some goal in order to fulfil some need or expectation.

To Mullins, therefore, people's behaviour is determined by what motivates them. Their performance is a product of both ability level and motivation level. He advises that if a manager is to improve the work of the organization, attention must be given to the level of motivation of its members. The school in a way is an organized organization with the headmistress as a manager, it therefore follows that if the manager encourages the staff to direct their efforts towards the attainment of goals of the school, then teachers are likely to stay and work.

Motivation is a complex subject and is influenced by many variables. Individuals have a variety of changing and often conflicting needs and expectations that they attempt to satisfy in a number of different ways.Needs and expectations can be categorized in a number of ways, for example, psychological and social motivation, or into intrinsic and extrinsic motivation (Mullins 2005). Extrinsic motivation is related to tangible rewards such as salary and fringe benefits, security, promotion, contract of service, the work environment and conditions of work. Intrinsic motivation is related to psychological rewards like the opportunity to use one's ability, a sense of a challenge and achievement, receiving appreciation, positive recognition and being treated in a caring and considerate manner.

In a school system, when a teacher becomes dissatisfied with his job environment, he may engage in any one of the following activities. He may exhibit aggressive behaviour. Aggression is a physical or verbal attack on some person or object (Mullins 2005). This may include malicious gossip about the headmaster. He or she may also choose to adopt withdrawal activities which include apathy, giving up or resignation, arriving at work late and leaving early, sickness and absenteeism, refusal to accept responsibility, avoiding decision making, passing work over to colleagues, or leaving the job altogether (Mullins 2005). 
The results of the study translate in the current study that if Zuarungu Senior High School teachers existence such as accommodation, welfare, teaching and learning materials etc.

\section{Maintenance or hygiene factors}

These factors include salary, job security, working conditions, level and quality of supervision, school policy and administration and interpersonal relations. These factors also prevent dissatisfaction. The hygiene factors are those that create dissatisfaction in one's job, but which when provided, do not necessarily cause satisfaction. Money is included as hygiene. The effects of the hygiene factors are short-lived and Herzberg attributes this to the fact that hygiene is external to the worker and therefore needs reinforcement. Teachers in Zuarungu Senior High School when adequately provided with the necessary conditions at the school, they may be satisfied at the school and continue reinforcement might let them stay longer. However, when teachers at Zuarungu Senior High School experience issues of dissatisfaction as mentioned by Mullins, they may also exhibit negative attitude towards teaching and even quit.

\section{Studies on Job Satisfaction}

For most people, it is undeniable that monetary compensation is a major rationale for working, no matter what other motivations or passions co-exist for the job. Earlier literature has shown more or less consistent views about the impact of salary or an increase in salary on decision to stay in teaching (e.g., Brewer, 1999; Hanushek, Kain, \&Rivkin, 1999; Ingersoll, 2001; Stinebrickner, 2001). Overall, higher salary is associated with lower teacher attrition, but the effect of salary is small and varies within characteristics of subpopulations. For example, using several logistic regression equation models, Hanushek, Kain, and Rivkin (1999) found that salary increases reduced the likelihood that teachers in Texas would leave their district, yet teacher mobility was much more strongly related to characteristics of the students than to salary. In addition, Brewer (2000) found a positive association between teacher salary and the retention rates of only female teachers in New York between 1975 and1990, using a discrete time hazard model.A series of influential studies conducted by Murnane and Olsen (1990, 2001), employing data from Michigan and North Carolina, demonstrated that teacher salary is an important determinant of the length of time that teachers stay in teaching. The results indicated that teachers who are paid more stay longer in teaching and teachers with higher opportunity costs, as measured by test scores or degree subject, stay in teaching less time than other teachers.

In deciding whether to remain or leave teaching, teachers make on-going assessments of the attractiveness of teaching relative to alternative occupations or activities that they might pursue. Attractiveness of the teaching profession and satisfaction in the workplace is closely associated with working conditions. Recently, however, researchers have explored the relationship between workplace conditions and teacher turnover (Baker \& Smith, 1997; Ingersoll, 2001). In general, these studies, similarly, employed factor analysis to extract factors of working conditions and logistic regression models to see the effects of the extracted factors on teacher commitment, and/or retention (e.g., Ingersoll, 2001; Weiss, 2002). Findings have been fairly consistent though indicators of working conditions were different, such that teachers who felt dissatisfaction over working conditions were more likely to leave the teaching profession. In addition, other studies have revealed that teachers are prone to leave schools for more economically and educationally advantageous places (Loeb, Darling-Hammond, \&Luczak, 2005).

Ingersoll (2001) investigated the effects of organizational conditions of the schools on teacher attrition, using the data from 1993-1994 School and Staffing Survey. He extracted four factors representing working conditions through exploratory factor analysis: advanced salary, administrative support, student discipline problems, and faculty influence. He found that, in particular, low salary, inadequate support from the school administration, student discipline problems, and limited faculty influence into school decision-making all contribute to higher rates of turnover, after controlling for the characteristics of both teachers and schools. In the similar context, Ingersoll et al. (2000) found that self-reported commitment to the teaching profession among working teachers was lower for teachers in secondary schools than for those in combined schools and higher for teachers in urban and suburban schools than for those in rural schools.

Krumboltz (2007) identified four factors that influence the nature of a career decision: genetic endowment and special abilities (e.g. gender, race, intelligence, physical characteristics), environmental conditions and events (e.g., social, cultural, political or monetary factors), learning experiences (e.g. job training opportunities, technological developments, and training resources), and task approach skills (e.g., set of skills, standards, values, work habits, perceptions, emotions, and cognitive process). Thus, individual career 
decisions are seen as outcomes of a combination of four factors that interact in different ways. Chapman (2004) and Chapman and Green (2006) expanded on Krumboltz' work and developed a public school teacher retention/attrition model. The model suggests that teacher retention is a function of:

(a) Teachers' personal characteristics (e.g., age, gender, and race),

(b) Educational preparation (e.g., degree obtained, quality of teacher preparation program, and student performance such as grade point average, course grades),

(c) Learning experiences (e.g., initial commitment to teaching and quality of first year teaching),

(d) Social and professional integration into teaching (e.g., a teacher's values, skills and abilities, and accomplishments), and

(e) External influences (e.g., employment climate, alternative employment opportunities).

Chapman (2004) and Chapman and Green (2006) tested the suggested model using four groups of University of Michigan graduates with teaching certificates. The groups included:

(a) Those who taught continuously,

(b) Intermittent teachers,

(c) Those who left teaching, and

(d) Those who never taught.

The researchers found that the groups differed in personal characteristics, educational experience/initial commitment, professional integration into teaching, external influences, and career satisfaction. They concluded that teacher retention/ attrition is a result of the social learning process. Turnover intention has been a substantial variable in relation to job satisfaction and actual turnover in organizational behaviour studies and applied psychology (Van Breukelen, Vander Vlist, \&Steensma, 2004; Vandenberg \& Nelson, 2009). Similar to job satisfaction, turnover intention has implications for job performance and organizational effectiveness. Teachers with high levels of turnover intention are less likely to devote themselves to teaching. Teachers with high levels of turnover intention may also be more likely to leave actually. However, the results of studies of relationship between intent to leave and actual behaviour have been mixed (Vandenberg \& Nelson, 2009). This is because actual turnover is more difficult to predict than intentions, as many external factors affect turnover behaviours such as childrearing (pregnancy), moving, family status, family income, and job alternatives.

A review of the research related to gender differences in turnover intentions and turnover rates showedmixed results. Some studies suggest that women report higher levels of turnover intentions (e.g., Miller \&Wheeler, 2002; Moncrief, Babakus, Cravens, \& Johnson, 2000; Schul\& Wren, 2002) and actual turnover (Mano-Negrin, 2003), than men. Research has suggested that these findings may be due to job dissatisfaction onthe part of women (which could be related to the lower level positions commonly held by women) or becausewomen have lower earnings and fewer opportunities for advancement (e.g., Blau\& Kahn, 2001). Some may speculate that these findings are related to statistical discrimination theory which suggests that employers "experiences may cause them to expect women to leave an organization sooner than men (Konrad \& Cannings,1997). Others have found that women experience a greater number of "shocks" or events that force them todecide to leave the organization (e.g., pregnancy and birth of a child). However, astudy of textile workers revealed that while women had a higher turnover rate than men, no gender differenceswere found in intentions to leave the organization (Weisberg \& Kirschenbaum, 2003). Still other studies ofmanagerial and professional positions have found no gender difference in turnover intentions (Rosin \& Korabik,2005; Xu, Veloski, Hojat, \& Fields, 2005). Some studies even found that men had higher turnover intention(Smith \& Calasanti, 2005). The number of years employees spend in an organization or what is often referred to as tenure is an important factor in many job-related issues. Tenure, as used in industrial/organizational psychology literature refers to the number of years that a person has been formally employed in an organization (Trimble, 2006).

Fewempirical studies on the relationship between tenure and turnover and turnover intentions are beginning toemerge (Gable, Hollon \& Dangello, 2004; Guper, 2009; Parasuraman \& Futrell, 2003; Schultz, Bigoness\&Gagnon, 1987; Trimple, 2006). In these previous studies, it was found that tenure is inversely related toturnover in such a way that those who have stayed longer in the organization have less intention to leave their organizations. Also, previous studies on tenure and turnover were carried out among employees in private business (e.g. Schultz, Bigoness \& Gagnon, 2007) or among missionaries (e.g.Trimple, 2006) and little are known about tenure and turnover intentions among employees in civil service especially in developing economies of Africa. 


\section{Conceptual framework}

The conceptual framework informing the study was based on Becker, 2001 human theory is presented below;

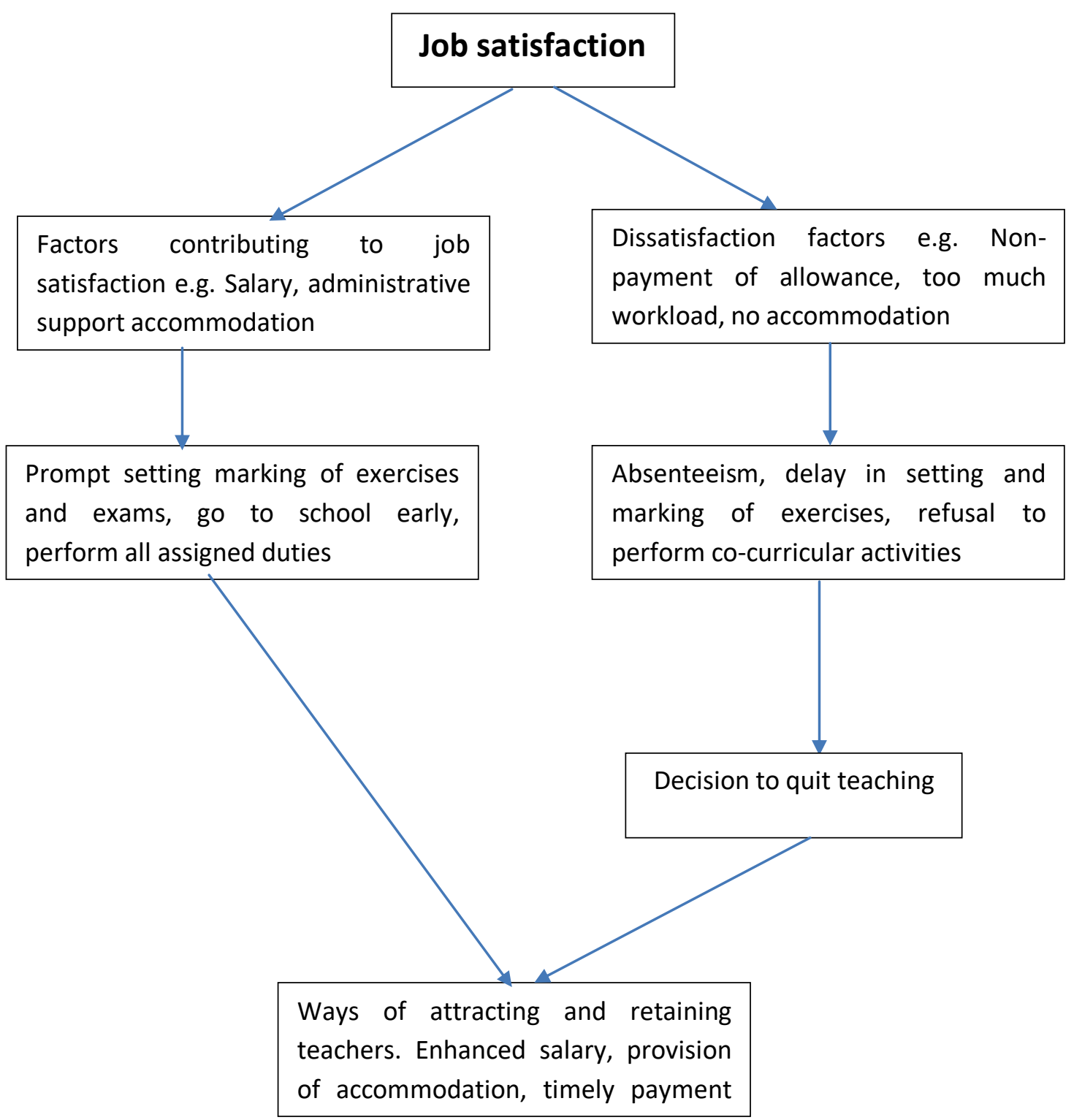

\section{Research Design}

An institutional case study was used in this study to investigate the relationship between job satisfaction and retention of teachers in Zuarungu Senior High School. Gall, Gall and Borg (2007) provide a definition which is based on its characteristics. To them, a case study is (a) the in-depth study of (b) one or more instances of a phenomenon (c) in its real-life context that (d) reflects the perspective of the participants involved in the phenomenon.Punch (2005) states that: The case study aims to understand the case in-depth, and in its natural setting, recognizing its complexity and its context. It also has a holistic focus, aiming to preserve and understand the wholeness and unity of the case. The case study approach has a number of strengths. The approach:

- Is able to capture and explore the complexity of phenomenon for a better understanding. This is what large scale quantitative studies, including a survey fail to achieve because, in most cases, they collect superficial information about the phenomenon for the purpose of generalization (Muijs, 2004).

- Requires the use of multiple methods to collect data, enabling it to be validated through triangulation (Denscombe, 2003; Yin 2003).

- Is action-oriented and therefore, the findings are useful for improving practice (Cohen et al., 2000). 
Notwithstanding these strengths, the case study approach has been critiqued in diverse ways, as shown below:

- Firstly, like other qualitative studies, the findings of case studies are difficult to be generalized. This is because such studies often concentrate on an instance or a few of a phenomenon and involves a relatively small sample size.

- Secondly, the approach requires a prolonged stay in the socio-cultural context of the participants for data collection and, therefore, negotiating access to such a place can be difficult.

- Thirdly, "the boundaries of the case can prove difficult to define in an absolute and clear-cut fashion" (Denscombe, 2008:48).

The researcher chose this design base on its strengths and it helps the researcher learn about job satisfaction and retention of teachers in Zuarungu Senior High School.

\section{Population}

Population refers to a group of individuals or people with the same characteristics and in whom the researcher is interested (Kusi, 2012). The research was carried out at Zuarungu Senior High School, located at Zuarungu in the Bolga East constituency in Bolgatanga Municipal. The target group for this research comprised the headmistress, teachers who were at post in Zuarungu Senior High School.

\section{Sample}

Sample is a group of elements (persons) from which data has been obtained (Atindanbila, 2013).A sample of 50 teachers, 25 males and 25 females were selected for the study. The respondents had the following characteristics, married, single, widowed, divorced and separated.

\section{Sampling Technique}

Sampling refers to the process of selecting a small part of the population in order to determine some qualities or characteristics of the whole (Alumode in Ezeliora et al, 2011). According to Ezeliora et al (2011), sampling becomes necessary when the population is large and cannot be researched readily. This involves defining the population, listing the units of the population, determining the sample size and drawing from the list. The important thing is that characteristics of selected participants should enable the researcher to make statistical generalization. Two main sampling techniques exist in research. These are probability sampling also called scientific sampling. The other is non-probability sampling also known as purposive sampling Elzeliora et al (2011). But this study made use of the probability sampling. The probability sampling technique include simple random, systematic, stratified and cluster sampling strategies. The probability sampling technique was used to get responses from the selected participants through simple random sampling. The researcher made sure every teacher was a potential respondent. This was done by administering the questionnaire to teachers who were present in school. They were given two days to answer and return questionnaires.

\section{Instrument for Data Collection}

A structured questionnaire was used to collect data in this study to investigate job satisfaction and retention of teachers in Zuarungu Senior High school in the Bolgatanga Municipal. A structured questionnaire is a series of questions, statements or items presented and the respondent is asked to answer correspond or comment on them in a way she or he thinks best. There is clear structure, sequence and focus (Cohen et al., 2000:248). A structured questionnaire is often used to collect quantitative and qualitative data. A structured questionnaire contains predetermined standardized questions or items meant to collect numerical data that can be subjected to statistical analysis. A structured questionnaire has much strength. In the first place, data collected through this instrument are easily analysed compared to qualitative instruments such as unstructured interview and observation. Again, most research participants feel more comfortable responding to pre-determined responses than items requiring them to express their views and feelings. Structured questionnaire can also be used with a large number of sample sizes unlike semi-structured interviews. However, a structured questionnaire has the following weakness; it is difficult to use the instrument to explore the feelings and experiences of research participants due to the structured nature of the responses 
(Kusi, 2012). Despite the above challenge, the researcher used this instrument due to the qualitative nature of the study.

A 4-part standardized questionnaire was the main data collection instrument.

Section A was on demographic data. Section B was the 18-item Job satisfaction scale developed by Brayfield and Rothe (1951) with a reliability coefficient of 0.87.This section tested teachers' job satisfaction. Examples of the job satisfaction items are, is your job like a hobby, is your job usually interesting enough to keep you from getting bored, Are you enthusiastic about your job?Section C was the 3item turnover intention scale developed by O'Driscoll\&Beehr's (1994) The Cronbach's alpha for the sample of turnover intentions was 0.91 . This section tested teachers' intentions to quit. Sample questions included, Does thoughts about quitting the job cross your mind, do you plan to look for a new job within the next 12 months, how likely is it that, over the next year, you will actively look for a new job outside? Section D was the 20-item scale measuring perception of work environment developed by Niehoff\& Moorman (1993).

The Cronbach's alpha for the sample was 0.7. This section tested teachers' perception of the working environment. Sample questions included;Does your manager clarify decisions and provide additional information when requested? Are job decisions applied consistently across all affected employees? Are Employees allowed to challenge or appeal job decisions made by the manager?The reliability coefficient of job satisfaction for this sample is 0.8.It can then be explained that the scale to a higher extent tapped the information it purported to measure. In comparison with the original reliability coefficient (0.87) it can be said that although there are differences, it is insignificant hence they are all reliable. The difference can be attributed to cultural variations and contextual variables. The Cronbach's alpha of turnover intention for this sample is 0.88. This can be explained that the scale to a higher extent tapped the information it purported to measure. In comparison with the original Cronbach's alpha for the sample (0.91) it can be said that although there are differences it is not all that significant hence they are all reliable. There could also be influential variables such as individual differences, cultural variations, contextual variables and personal characteristics. The Cronbach's alpha of teachers' perception of work environment for this sample is 0.6. It can then be explained that the scale to a moderate extent tapped the information it purported to measure. In comparison with the original Cronbach's alpha it can be said that there are differences and this can be attributed to individual differences, contextual variables and personal characteristics.

\section{Procedure for data collection}

The researcher sought permission from the headmistress to allow teachers be part of the research. The researcher took time and explained to teachers the purpose of the study and how significant the study would be to the school and Ghana Education Service as a whole. Their cooperation for the study was also solicited for by the researcher.

An appointment was booked with prospective respondents (school) after permission was granted. The questionnaires were personally administered by the researcher as scheduled. To ensure availability of respondents at a time, questionnaires were administered when the school was on break during school hours. The questionnaires were collected two days after they had been administered.

\section{Scoring}

Responses on the job satisfaction questionnaire were scored on a 5-point Likert scale which ranged from: 'Strongly agree' for a score of 1 , 'agree' for 2, 'undecided' for 3, 'disagree' for 4 and 'Strongly disagree' for 5 .

\section{Data Analysis}

The quantitative responses were coded under different headings and variables after the data were collected. Statistical Package for Social Sciences (SPSS) version 17.0 software was used for data analysis. All the questionnaires were entered and the responses coded. The data were presented in the form of tables for discussion.

\section{Teachers' Demographic Data}


Age Distribution: Zuarungu Senior High School hah a youthful staff as shown in table 1 below. Seventeen teachers $(68 \%)$ of the staff of 50 (i.e. 36 males and 14 females) fell within the ages of 25-39 years. This means that the school had a young and energetic workforce that was capable of delivering their work.

Table 1: Age Distribution of Respondents

\begin{tabular}{|lccc|}
\hline Sex & Age & Frequency & $\%$ \\
\hline & $25-29$ & $5,(4)$ & $10,(8)$ \\
\multirow{4}{*}{ Male (Female) } & $30-34$ & $13,(6)$ & $26,(12)$ \\
& $35-39$ & $9,(4)$ & $18,(8)$ \\
& $40-44$ & $6,(0)$ & $12,(0)$ \\
Total & $45-49$ & $3,(0)$ & $6,(0)$ \\
\hline
\end{tabular}

Source: Field of Study, 2020

\section{Sex Distribution of Respondents}

From table 2 below, the respondents in the study were predominantly males (36 out of 50) forming $72 \%$ of the total number of respondents. The female respondents were $28 \%$ of the total number of respondents

Table 2: Sex Distribution of Respondents

\begin{tabular}{|lcc|}
\hline Sex & Frequency & Percentage $\%$ \\
\hline Male (Female) & $36,(14)$ & $72,(28)$ \\
\hline Total & 50 & 100 \\
\hline
\end{tabular}

Source: Field of Study, 2020

\section{Marital Status of Respondents}

Marital status is believed to contribute greatly to the retention of staff in a school. Data from Table 3 shows that in Zaurungu Senior High School, for the male respondents 16, (32\%) were married,10,(20\%) were singles, there was no divorcee, 5, (10\%)were widowed and 5,(10\%) males were separated. Out of 14 female teachers, $4,(8 \%)$ were married, $8,(16 \%)$ were single $0,(0 \%)$ were divorced and $2,(4 \%)$ were separated from their spouses.

Table 3: Marital Status of Respondents

\begin{tabular}{|llcc|}
\hline Sex & Marital status & Frequency & $\%$ \\
\hline Male (Female) & Married & $16,(4)$ & $32,(8)$ \\
& Single & $10,(8)$ & $20,(16)$ \\
& Divorced & $0,(0)$ & $0,(0)$ \\
Separated & Widowed & $5,(0)$ & $10,(0)$ \\
\hline
\end{tabular}

$36,(14) \quad 72,(28)$

\section{Source: Field of Study, 2020}

\section{Number of years of Service in the school}

Records on the number of years of service of teachers (Table 4) showed that majority of the respondents (10 out of 35, i.e. $20 \%$ of the total number) had served for more than 10 years in the Ghana Education Service. However, majority of the female respondents (8) had worked for not more than 5 years $(16 \%)$ in the school. Others i.e. 14 males $(28 \%)$ and 6 females $(12 \%)$ had gone beyond 16 years. There were therefore many teachers with rich teaching experience on the staff. The experience of the teachers had been recognized as a major contributory factor to the teacher's classroom instructional and managerial effectiveness. This means that on the whole, there would be effective teaching in Zuarungu Senior High School.

Table 4: Tenure of Service in the School 


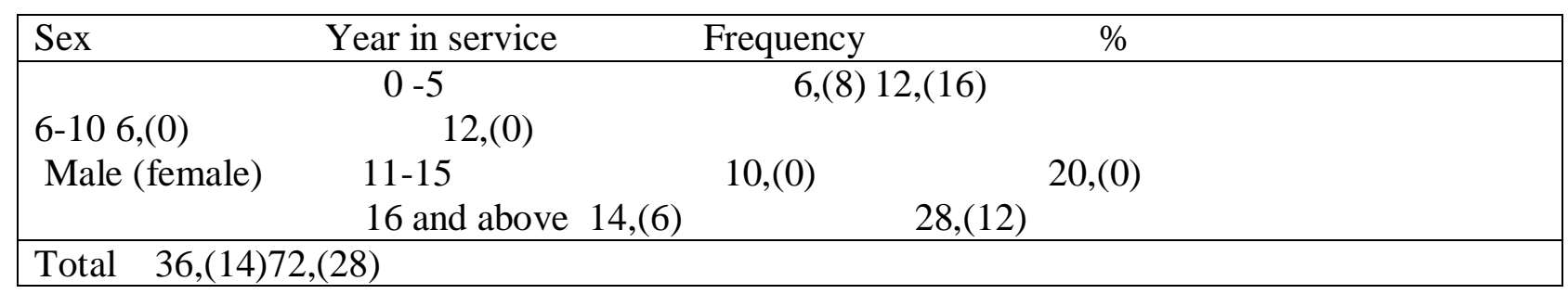

\section{Source: Field of Study,2020}

\section{Qualification of Teachers}

Findings showed that out of the total number of male respondents of 36,2 i.e. $4 \%$ were diploma holders; $27 \%$ male teachers, i.e. 54\% were degree holders and 3, $6 \%$ ) had master's degree. Among the female respondents, it was found out that $11,(22 \%)$ of female teachers had bachelor's degree and 3, $(6 \%)$ of them were master's degree holders.

Table 5: Qualification of Respondents

\begin{tabular}{|llllllll|}
\hline Qualification & Male & \multicolumn{2}{c|}{$\%$ Female\% } & & & \\
\hline Diploma & 2 & 4 & 0 & 0 & & & \\
Degree & 27 & 54 & & 11 & 22 & \\
Masters & 7 & 14 & & 3 & 6 & \\
\hline & 36 & 72 & & 14 & 28 \\
\hline
\end{tabular}

\section{Source: Field of Study, 2020}

\section{Rank of Respondents}

In terms of rank within the Ghana Education Service, Zuarungu Senior High School had six (6)male assistant directors who constituted $12 \%$, of the female respondents, four (4), $8 \%$ were in the rank of assistant director. Twenty eight (28) male teachers representing 56\% were principal superintendents and 10ie females, $20 \%$ were principal superintendents. Two male teachers (4\%) were senior superintendent and nofemale teacher was in this category. The least rank was senior superintendent and there was no superintendent among the teachers in Zuarungu Senior High School.

Table 6: Rank Distribution of Respondents

\begin{tabular}{|llcc|}
\hline Sex & Rank & Frequency & $\%$ \\
\hline \multirow{3}{*}{ Male (female) } & Assistant t Director & $6,(4$ & $12,(8)$ \\
& Principal superintendent & $28,(10)$ & $6,(20)$ \\
& Senior superintendent & $2,(0) 4,(0)$ & \\
& superintendent & $0,(0)$ & $0,(0)$ \\
\hline Total & & $36,(14)$ & $72(28)$ \\
\hline
\end{tabular}

\section{Source: Field of Study, 2020}

Research Question 1: What factors contribute to job satisfaction among teachers at Zuarungu Senior High School?

Questionnaire Item 10: The following factors contribute to job satisfaction; advanced salary, administrative support and accommodation.

Table 7: Factors that contribute to job satisfaction

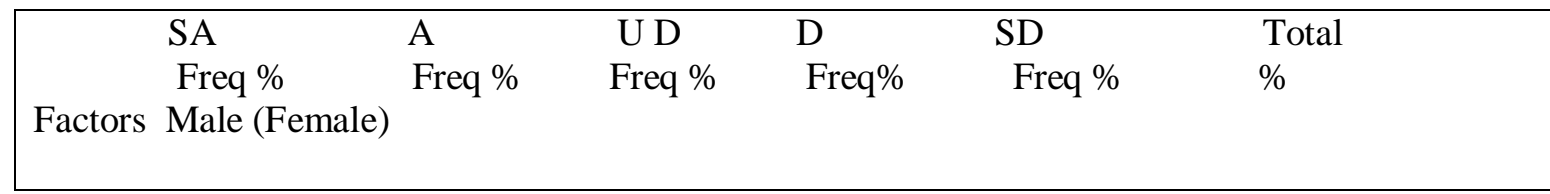




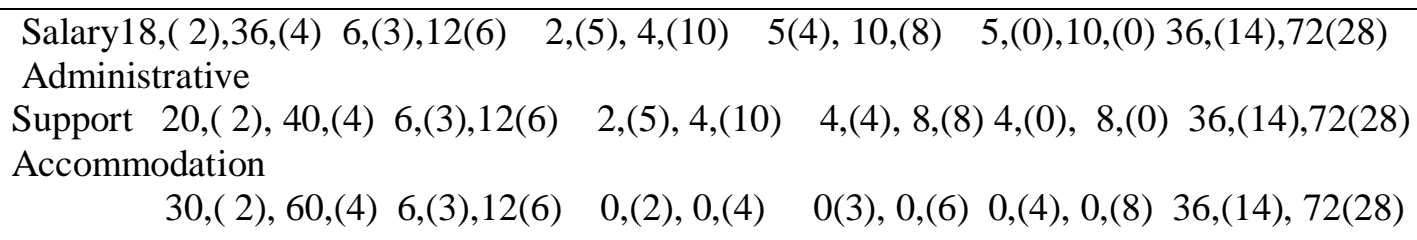

\section{Source: Field of Study, 2020}

As indicated in table 7 above, the factors such as advance salary, administrative support, accommodation and interpersonal relationship are very important and contributedto job satisfaction among teachers in Zuarungu Senior High School. Eighteen of the male teachers representing (36\%) strongly agreed that salary was a factor that contributed to job satisfaction. Two female teachers representing (4\%) of the population strongly agreed that salary, was a factor contributing to job satisfaction. Six, (12\%) of male teachers agreed that salary was a factor that contributed to job satisfaction while three, $(6 \%)$ of female teachers also agreed that salary was a factor that contributed to job satisfaction. Two, $(4 \%)$ of male teachers were undecided as to whether salary was a factor that contributed to job satisfaction or not while five, $(10 \%)$ of female teachers were undecided. Five, (10\%) of male teachers disagreed that a factor such as salary contributed to job satisfaction whereas four, $(8 \%)$ of female teachers disagreed to the statement. Five, $(10 \%)$ male teachers strongly disagreed that salary was a factors that contributed to job satisfaction. No female teacher strongly disagreed to the statement.

On the issue of administrative support as a factor for job satisfaction, twenty of the male teachers representing (40\%) strongly agreed that administrative support was a factor that contributed to job satisfaction. Two female teachers representing (4\%) of the population strongly agreed that administrative support was a factor contributing to job satisfaction. Six, (12\%) of male teachers agreed that administrative support was a factor that contributed to job satisfaction while three, $(6 \%)$ of female teachers also agreed that administrative support was a factor that contributed to job satisfaction. Two, $(4 \%)$ of the male teachers were undecided as to whether administrative support was a factor that contributed to job satisfaction while five, $(10 \%)$ of the female teachers were undecided. Four, $(8 \%)$ of male teachers disagreed that a factor such as administrative support contributed to job satisfaction whereas four, $(8 \%)$ of female teachers disagreed to the statement. Four, $(8 \%)$ male teachers strongly disagreed that administrative support was a factor that contributed to job satisfaction. No female strongly disagreed to the statement.

On accommodation, thirty of the male teachers representing (60\%) strongly agreed that accommodation was a factor that contributed to job satisfaction. Two female teachers representing (4\%) of the population strongly agreed that accommodation was a factor contributing to job satisfaction. Six, (12\%) of male teachers agreed that accommodation was a factor that contributed to job satisfaction while three, $(6 \%)$ of female teachers also agreed that accommodation was a factor that contributed to job satisfaction. No male teacher, $(0 \%)$ was undecided as to whether accommodation was a factor that contributed to job satisfaction while two, (4\%) of female teachers were undecided. No male teacher disagreed that a factor such as accommodation contributed to job satisfaction whereas 3, $(6 \%)$ of female teachers disagreed to the statement. No male teacher strongly disagreed that accommodation was a factors that contributed to job satisfaction four female, (8) teachers strongly disagreed to the statement.

From the data analyzed above, teachers in Zuarungu Senior High School considered salary, provision of accommodation and administrative support as factors that contributed to job satisfaction and it answered research question one; what factors contribute to job satisfaction among teachers at Zuarungu Senior High School. From the data analysed above, teachers in Zuarungu Senior High School considered salary, provision of accommodation and administrative support as factors that contributed to job satisfaction this answers research question one which is what factors contribute to job satisfaction among teachers at Zuarungu Senior High School?

Research Question 2: In what ways does job dissatisfaction affect teachers' performance in Zuarungu Senior High School? 
Questionnaire Item 7: The following ways affect my job performance; irregular setting and marking of exercises and exams, absenteeism and refusal to perform co-curricular activities.

Table 8: Ways that Job dissatisfaction affect Job performance

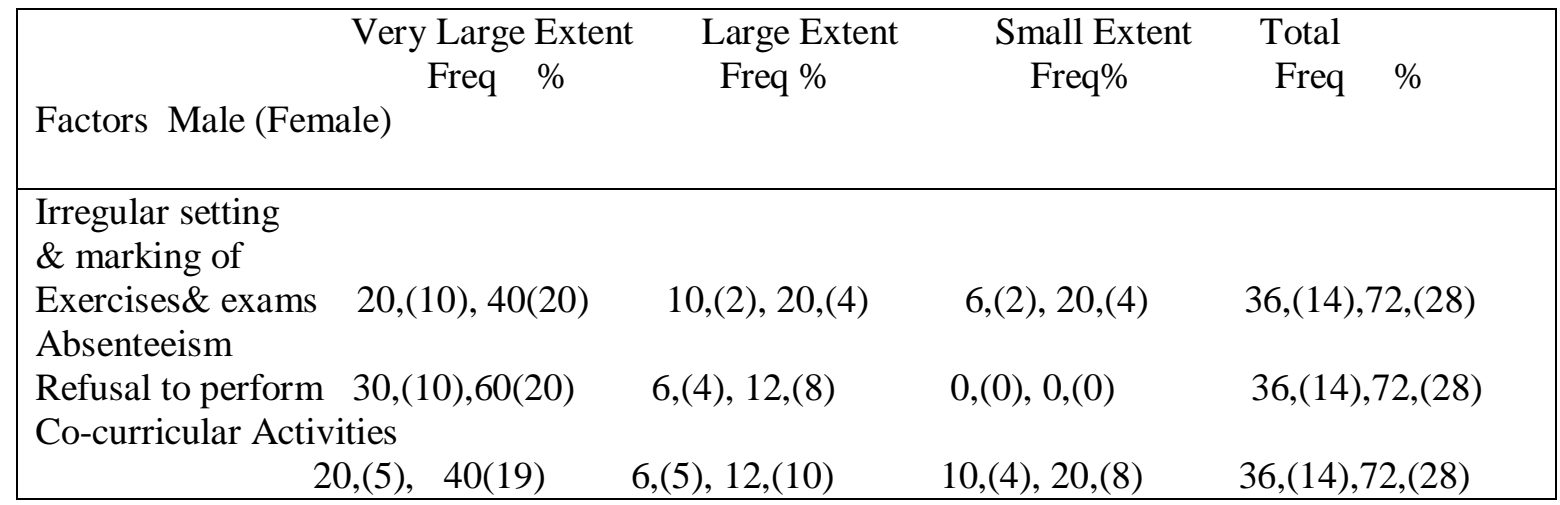

\section{Source: Field of Study, 2020}

Out of the 50 teachers in Zuarungu Senior High School, those who agreed that irregular setting and marking of exercises and exams are the impact on job performance due to lob dissatisfaction to a very large extent were 20 representing $40 \%$ of the male teachers while 10 female teachers representing $20 \%$. On the same the issue of absenteeism, 30 of male teachers 10 female teachers to a large extent agreed that absteesim is the impact of job dissatisfaction on job performance and they represented $60 \%$ and $20 \%$ of the population. Those who agreed that absenteeism to a large extent was an impact of job dissatisfaction on job performance were 6 male and 4 female teachers representing 12\% and $8 \%$. For those who agreed to a small extent that absenteeism was an impact on job performance because of dissatisfaction from the job were 0 male and 0 female teachers representing $0 \%$ and $0 \%$ of the population.

Twenty male and 5 female teachers representing $40 \%$ and $10 \%$ respectively to very large extent agreed that job refusal to perform co-curricular activities because of job dissatisfaction. Those who agreed to a small extent were 10 and 4 representing $20 \%$ and $8 \%$ of male and female teachers respectively. The data in table 7 revealed that irregular setting and marking of exercises and exams, absenteeism and refusal to per cocurricular activities were the impact of job dissatisfaction on job performance in Zuarungu Senior High School. This answers research question two which is in what ways does job dissatisfaction show in teachers' performance in Zuarungu Senior High School?

\section{Discussion}

The study investigated into job satisfaction and retention of teachers (a case study in Zaurungu Senior High School Bolgatanga).This section contains headings reflecting on the tworesearch questions, it gives a detailed explanation of findings on the topic. It reveals the extent to which data gathered on the field supported existing theories and empirical research findings reviewed to complement the study.

\section{Teacher Characteristics Associated with Attrition.}

Ehrenberg et al (2003 \&1993) stated that one of the major principles of human capital theory is that the greater the amount of knowledge and skills accumulated in a job over time from investments in education and job training, the lower one's probability of attrition from that occupation. In terms of the years spent by teachers as an influencing factor for quitting a job and their intentions to quit contradicted with that of Ehrenberg et al (2003). The findings obtained rather confirmed that teachers who had spent enough time in the teaching profession had intentions to quit, the situation was that even though, majority of teachers had intentions of quitting teaching, unfortunately these teachers were those who were of age 40-44 years. This contradiction in the findings could be attributed to cultural variations or individual differences and this needs further investigation. The results showed that more male teachers than female teachers would want to quit teaching. Thus, the data gathered showed males more frequently had intentions of leaving teaching than females. The growing demand for teachers is not only caused by large increases in student enrolments and in 
teacher retirements, class size reduction, and insufficient production of college graduates from teacher education programs another key source of this challenge lies in a high rate of teacher attrition.

Research Question 1: What factors contribute to job satisfaction among teachers at Zuarungu Senior High School?

This research question sought to find out what factors contribute to job satisfaction among teachers in Zuarungu Senior High School. Locke and Lathan (1976) gave a comprehensive definition of job satisfaction as pleasurable or positive emotional state resulting from the appraisal of one's job or job experience. Locke and Lathan clarified that employees become satisfied if their working conditions, that is, autonomy, training and salary meet their personal demands. Comparative to this study, the data gathered on teachers in Zuarungu Senior High School confirmed that working conditions contributed to job satisfaction. Practically, teachers saw the satisfactory nature of their job from the kind of teaching conditions in which they found themselves. This means that the more they perceived their work conditions as not satisfactory the less they become satisfied. Job satisfaction has been defined in several ways but its materialization has always raised many questions. From the perspective of human capital theory, monetary benefits (e.g. health/life insurance, pensions) from the teaching profession can be viewed as returns on investment in education and training. Such training intuitively make individuals more productive, resulting in higher wages and the trade-offs associated with the costs (Becker, 1993).The analysis revealed that a greater number of the teachers disagreed that they have satisfaction for the teaching jobmeaning most of them saw their working conditions to be very poor. According to the teachers, their working conditions did not truly reward them if they consider the great impact they make on the society, specifically, the education given by them to students.

From the data analyzed above, teachers in Zuarungu Senior High School considered salary, provision of accommodation and administrative support as factors that contributed to job satisfaction this answers research question one which is what factors contribute to job satisfaction among teachers at Zuarungu Senior High School?

Research Question 2: In what ways does job dissatisfaction affect teachers' performance in Zuarungu Senior High School?

This research question focused on what ways job dissatisfaction affect teachers' performance in Zuarungu Senior High SchoolAnalysis from Table 8 was used to answer research question two.Dias-Serrano (2005) stated that job satisfaction is considered a strong predictor of overall individual well-being as well as a good predictor of intentions of decision of employees to leave a job. The issue of job satisfaction is of a considerable importance for both employers and employees. Employer benefits from satisfied employees as they are more likely to profit from their productivity. Today, a few people would disagree that the teacher is the most influential school related factor affecting the quality of education a student receives (DarlingHammond, 1999; Sanders \& Rivers, 1996). Some researchers argued that dissatisfied teachers are less likely to do their best work in the classroom (Evans, 2001). The findings obtained in this study confirmed that of Evans, it was seen that because teachers were not satisfied with their job, they felt reluctant, bored and unhappy to go to school left alone to teach. Quality teaching of these teachers was questionable. They taught their students without any motivational interest. The data in table 7 revealed that irregular setting and marking of exercises and exams, absenteeism and refusal to per co-curricular activities were the impact of job dissatisfaction on job performance in Zuarungu Senior High School. This answers research question two which is in what ways does job dissatisfaction show in teachers' performance in Zuarungu Senior High School?

\section{Conclusion}

The study investigated job satisfaction and retention of teachers in Zuarungu Senior High School in the Bolgatanga Municipality. The study established that work condition is a factor contributing to job satisfaction. From the data analyzed for research question one, teachers in Zuarungu Senior High School considered salary, provision of accommodation and administrative support as factors that contributed to job satisfaction this answers research question one which is what factors contribute to job satisfaction among teachers at Zuarungu Senior High School.The data in table 7 revealed that irregular setting and marking of exercises and exams, absenteeism and refusal to per co-curricular activities were the impact of job 
dissatisfaction on job performance in Zuarungu Senior High School. This answers research question two which is in what ways does job dissatisfaction show in teachers' performance in Zuarungu Senior High School?

\section{Recommendations}

From the findings made so far, the following recommendations should be considered:

- Ministry of Education should impress upon the Ministry of Finance and Economic Planning to review and pay the appropriate monthly allowance to teachers.

- Satisfaction factors such as provision of accommodation and payment of responsibility allowances should done by government and other stakeholders in education rise the morale of teachers to improve the teachers' performance.

- Dissatisfaction factors such as unfair distribution of workload should as much as possible be reduced because they inhibit teacher-motivation and lower morale in teachers.

- Teachers should relate well with their colleagues in order to get motivated to derive maximum satisfaction from their work.

- It is not only monetary rewards that motivate. In these days when government support for education seems low, parents, opinion leaders, non-governmental organization and other educational stakeholders to improve standards in schools by improving infrastructure in our schools by constructing good classroom bocks.

- The headmasters and mistresses should be fair in their dealings with their teachers that good interpersonal relationship to promote harmony.

\section{Suggestions for further research}

The researcher wishes to make these suggestions for further research:

It is suggested that the research should be widened to cover more schools in the municipality. This will make the findings of such an investigation more representative and by extension more valid.

Results from findings could not be generalized. Logistic regression analysis was not carried on the teacher characteristics on turnover intentions, rather; frequencies and percentages were used to explain the situation.

Acknowledgements: Elizabeth Ayenga Ayamdor (Mrs.), Rose Adjei (Mrs.), Frederica Awinbono Aduko,Adelwine Aduko, Gifty Ayamba- Headmistress Kongo SHS, Diana Adutwumwaa- Offinso College of Education and Lawrencia Adjei, Barekese SHS

\section{References}

[1] Baker, D., \& Smith, T. (1997). Teacher turnover and teacher quality: Refocusing the Teachers College Record, 99(1), 29-35.

[2] Becker, G. S. (1993). Human capital: A theoretical and empirical analysis with specialreference to education (3rd ed.). Chicago: University of Chicago Press.

[3] Brewer, D. (1996). Career paths and quit decisions: Evidence from teaching. Journal ofLabor Economics, 14(2), 313-339.

[4] Chapman, D. W. (1984). Teacher retention: The test of a model. American EducationalResearch Journal, 21(3), 645-658.

[5] Chapman, D. W., \& Green, M. S. (1986). Teacher retention: A further examination. The Journal of Educational Research, 79(4), 273-279.

[6] Darling-Hammond, L. (1999). Solving the dilemmas of teacher supply, demand, and standards: How we can ensure a competent, caring, and qualified teacher for every child. New York, NY: National Commission on Teaching \& America's Future.

[7] Darling-Hammond, L. (2000). Teacher quality and student achievement: A review of state policy evidence. Education Policy Analysis Archives, 8(1).

[8] Dawis, R. V., \& Lofquist, L. H. (1984). A psychological theory of work adjustment:An individual differences model and its applications. University of Minnesota Press. Minneapolis 
[9] Dawis, R. V. (1994). The theory of work adjustment as convergent theory. Convergence in career development theories: Implications for science and practice. (pp. 32-43). Palo Alto, CA: CPP Books.

[10] Dawis, R. V., \& Lofquist, L. H. (1993). Rejoinder: From the TWA to PEC. Journal of Vocational Behavior, 43, 113-121.

[11] Evans, L. (2001). Delving deeper into morale, job satisfaction and motivation among education professionals: Re-examining the leadership dimension. Educational Management Administration, 29, 291-306.

[12] Ehrenberg, R. G., \& Smith, R. S. (2003). Modern labor economics: Theory and public policy (8th ed.). New York, NY: Addison Wesley Longman, Inc.

[13] Grissmer, D. W., \& Kirby, S. N. (1997). Teacher turnover and teacher quality. Teachers College Record, 99(1), 45-56.

[14] Hanushek, E. A., Kain, J. F., \& Rivkin, S. G. (1999). Do higher salaries buy better teachers?(Working Paper No. 7082). Cambridge, MA: National Bureau of Economic Research.

[15] Herzberg, F. (1968). Work and the nature of man. London: Staple Press.

[16] Ingersoll, R. M. (2001). Teacher turnover, teacher shortages, and the organization of schools(No. Document R-01-1). Seattle, WA: University of Washington, Center for the Study of Teaching and Policy.

[17] Ingersoll, R. M. (2003a). Is there really a teacher shortage? Seattle, WA: Center for theStudy of Teaching and Policy.

[18] Judge, T. A., Bono, J. E., \& Locke, E. A. (2000). Personality and job satisfaction: The mediating role of job characteristics. Journal of Applied Psychology, 85(2), 237-249.

[19] Kirby, S. N., \& Grissmer, D. W. (1993). Teacher attrition: Theory, evidence, and suggestedpolicy options. Santa Monica, CA: RAND

[20] Loeb, S., Darling-Hammond, L., \& Luczak, J. (2005). How Teaching Conditions Predict Teacher Turnover in California Schools. Peabody Journal of Education, 80(3), 44-70

[21] Macdonald, D. (1999). Teacher attrition: a review of literature. Teaching and TeacherEducation, 15(8), 835-848

[22] Murnane, R. J., \& Olsen, R. J. (1990). The effects of salaries and opportunity costs on duration in teaching: Evidence from North Carolina. Journal of Human Resources, 25(1), 106-124.

[23] Ostroff, C. (1992). The relationship between satisfaction, attitudes, and performance: Anorganizational Level Analysis. Journal of Applied Psychology, 77, 963-974.

[24] Pfeiffer, M., \& Urich, D. P. (1997). Job satisfaction among America's teachers: Effects of workplace conditions, background characteristics, and teacher compensation (Statistical Analysis Report No. NCES 97-471). Washington, DC: National Center for Education Statistics.

[25] Vandenberg, R. J., \& Nelson, J. B. (1999). Disaggregating the motives underlying turnover intentions: When do intentions predict turnover behaviour? Human Relations,52(10), 1313-1336.

[26] Van Breukelen, W., van der Vlist, R., \& Steensma, H. (2004). Voluntary employee turnover: Combining variables from the 'traditional' turnover literature with the theory of planned behaviour. Journal of Organizational Behaviour, 25, 893-914. 